\title{
The Perception of Time in Air transport - What a Delay is accepted by Air Travellers?
}

\author{
Andreas Wittmer ${ }^{1, a, *}$ and Christian Laesser ${ }^{1, b}$ \\ ${ }^{1}$ University of St. Gallen, Dufourstrasse 40a, CH-9000 St. Gallen, Switzerland
}

\begin{abstract}
This paper is about the perception of time by air travellers on business trips. Time is becoming a more relevant factor at airports due to all security checks. Furthermore, punctuality of airlines becomes an increasingly relevant factor due to overfilled airspaces around mega hubs. The question which arises is what level of delay is still accepted by air passengers on business trips without creating dissatisfaction with the delayed airline and if the accepted delay changes with frequency of air travels by business passengers. The sample includes 2834 air travellers which were interviewed before they were entering their flights at gates or in business lounges. The results reveal that a delay up to 30 minutes is acceptable in air travel. The more a passenger travels by plane the lower is the level of acceptance towards delays or the more punctuality becomes a basic factor and a power factor.
\end{abstract}

KEYWORDS: Aviation, air travellers, airline business travellers, time, punctuality.

\footnotetext{
${ }^{\text {a }}$ Andreas Wittmer, $* 1973$, is lecturer of aviation and tourism and holds the position of senior researcher at the Institute for Public Services and Tourism and is managing director of the Center for Aviation Competence at the University of St. Gallen. His research interests include air transport, where he is specifically interested in airlines and airports. In the field of tourism his interests are within the connection between tourism and transport and destination management.

* Corresponding author: phone +41 (0)71 224 2525, andreas.wittmer@unisg.ch (Andreas Wittmer)

${ }^{b}$ Christian Laesser, $* 1963$, is professor of tourism and service management and holds the position of senior researcher and deputy director at the Institute for Public Services and Tourism at the University of St. Gallen. His research and professional interests include consumer behaviour in the service industry, the financing and management of tourism core tourism companies (with special focus on success/ risk drivers in the hospitality industry), issues with regard to destination management (with special focus on marketing, network and organisational topics) as well as service management in the hospitality industry.
} 


\section{INTRODUCTION AND RESEARCH OBJECTIVE}

This paper is about the perception of time by air travellers on business trips. Time is becoming a more relevant factor at airports due to all security checks. Furthermore, punctuality of airlines becomes an increasingly relevant issue due to overfilled airspaces around mega hubs. Time is perceived as a sequence which is split into milliseconds. Intervals of time divide and examine the interdependence of objective, physical parameters from psychological aspects and psychological measurable factors. For an activity which needs a lot of thinking and uses intellectuality, time is perceived longer. Activities which do not need a lot of thinking make one perceive the time shorter. When travelling a specific route the first time, it is perceived more time consuming then if it is travelled regularly. The question which initiated this research was if total travel time is perceived differently if there is a delay versus if there is no delay of air travel services. Furthermore, the acceptance level of delays is of interest. The overall hypothesis which is going to be addressed in this study is: "The higher the punctuality the higher is the probability that the punctuality becomes a basic factor. In other words with an increasing delay perspective punctuality becomes an enthusiastic factor." The hypothesis is addressed by using the Kano research and analysis method which aims at implicit rather than explicit results.

\section{LITERATURE REVIEW}

The topic of air travel delays at airports induces an understanding of the perception of travel time. Travel time perception depends on the perception of time and the perception of distance. For example a person travelling on a specific route from $a$ to $b$ the first time, might perceive the travel time longer then a person travelling on a specific rout for the 10th time. Time is perceived as a sequence or as intervals which are split in milliseconds. The perception of the presence, meaning the dissolution of the time flow in a cognitive wholeness lies about at three seconds (Laesser 2006). There exists a psychological phenomenon about the feeling of time. If an objective process needs a high level of intellectual action, the process is perceived as more time consuming. If an objective process needs less intellectual action, the process is perceived as less time consuming (Laesser 2006). Einstein (1916) defined in his research the relativity of time the interaction between matter on one hand, space and time on the other. In its core statement, gravitation leads back towards a geometric phenomenon in a curved 4-dimensional space-time. The body clock is different then the mental clock, because the mental clock is 
distensible. Consciously perceived movements slow the subjective perception of time down especially in case of unpleasant situations. Pleasant situations increase the speed of subjective time because of the concentration on the affair. Memorisation is exactly opposite (Klein 2006). In eventful times there is a lot of information saved in the mind and thus the time period feels long, whereas in the opposite non-eventful times time periods feel short in retrospect, due to a low amount of saved information in the brain. Therefore, the more information is saved over a time period, the longer this time period is perceived (Klein 2006).

The concept of the cognitive distance creates a time perception problem. Geographic distance, costs for the travel choice between origin and destination, the frequency a specific route or distance is travelled, attractivity of the route and finally the choice of the means of transport influence travel time perception.

Figure 1: Perception of travel time

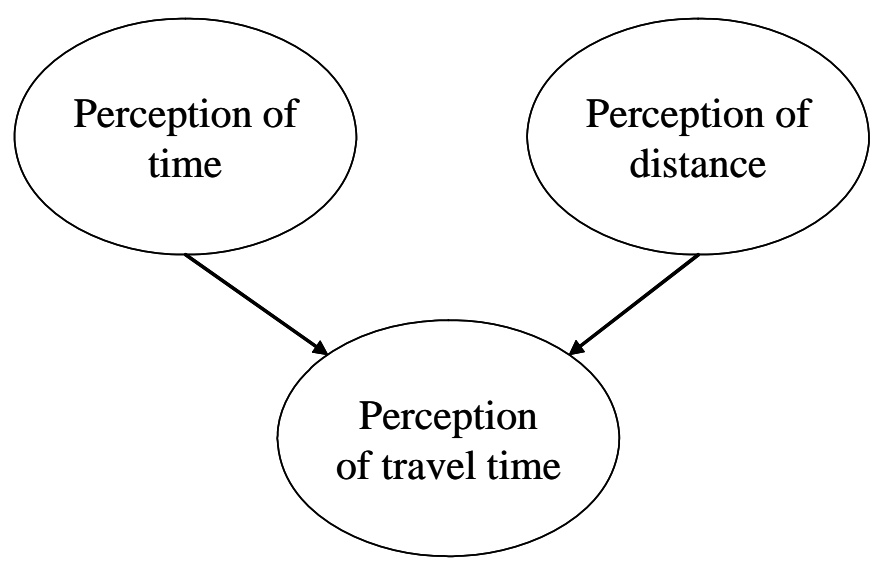

Source: The authors

The weight of the travel time is substantially dependant on the rationale of a trip. Business trips are comparatively more time sensitive then leisure trips (Mackie et al. 2003; Hensher 1997, Laesser \& Wittmer 2006). Furthermore, travel time clearly overrules other travel choice parameters in many cases (Mandel et al. 1997).

Habitualness is a further central determinant which can be derived from Fishbein and Aizen's (1975) planned behaviour approach. But different studies have indicated that habitualness is 
not necessarily resistant against changeable incentives like for example price or travel time of alternative suppliers. Thus, suppliers can only assume medium loyalty of their customers (Bamberg et al. 2003).

Furthermore, a large number of matters can restrict the freedom of choice and by this limit the objectivity of different choice parameters (Last \& Manz 2003; Heggie 1977). Capability constraints, coupling constraints as well as legal constraints are such parameters. Such constraints play especially an important role in business travel, which is dominated by appointments. Especially equality respectively equivalence of costs and prices become an important factor of the service quality (Ben-Akiva et al. 2002). For example in the air traffic between Europe and Central Asia partly livelong transfer connections are taken into account to take a save trip with a save airline.

For this study travel time was defined as the time from the home to the destination, not only the time from airport to airport. The study focused on delays of airline, which result in longer waiting times for passengers at airports. The survey aimed at gathering data about the acceptability of delays at airports and the critical level of delay time.

\section{METHODOLOGY AND DATA}

The data were collected at Zurich airport during one week. Research was conducted at gates and in business lounges. Mainly business and economy class passengers were included in the study. Respondents had to answer some demographic questions (place of living, job, education, place of work, industry of work). Furthermore, information about their flights and flight behaviour was collected (reason for flying, flight intensity, choice of upstream transport means, development of flight frequencies, preferred flight times, etc.). To receive some implicit data, which is less influenced by actual distractions, some of the questions were asked by using the Kano method. Totally 3900 questionnaires were handed out to air passengers of whom 2834 were returned and resulted in a response rate of $72.65 \%$. The results do not intend to be fully representative, but rather provide an insight in to the behaviour of air passengers at Zurich airport (Laesser \& Wittmer 2006). 
The Kano model (Sauerwein et al. 1996) was chosen for the analysis because it values different functions and evaluates them by using the means-end-chains method. By that the relevant functions evolve. Furthermore, the specific method, using functional and dysfunctional questions filters deviations from the truth and enhances in implicit results. The long term object of this model is to improve customer satisfaction with regard to important product features in order to establish tenable competitive advantages. The model measures if the customer is satisfied by the level the requirements are fulfilled. This is generally measured by dividing into three major types of product requirements:

- First, must-be requirements (basic factors) must be fulfilled; otherwise the customer is extremely dissatisfied. They are taken for granted. Satisfaction is related digressively to the degree of performance respectively quantity related to quality. An increase of performance is solely able to prevent dissatisfaction, but not increase satisfaction.

- Second, with regard to one-dimensional requirements (power factors), customer satisfaction is proportional to the level of fulfilment. Satisfaction is linearly related to the degree of performance. An increase of performance of one unit produces an increase of satisfaction by one unit as well.

- Third, attractive requirements (enthusiasm factors) are product criteria which have the greatest influence on the satisfaction of a customer with a given product. Satisfaction is related progressively to the degree of performance concerning quantity and quality. An increase of performance increases satisfaction in an above average degree. A decrease generates no dissatisfaction though.

Figure 2 shows Kano's model of customer satisfaction, which was applied for the analysis of this research. It was the goal to find differences of passengers concerning delays according to the frequency of their air travel. For this purpose the data was grouped into five quintiles for a more differentiated analysis:

- Quintile 1: one or less business related flight per year (e.g. non flyers resp. leisure flyers) represented by $0.2 \%$ of the sample.

- Quintile 2: two business related flights per year (e.g. non-frequent flyers) represented by $1.5 \%$ of the sample.

- Quintile 3: 3-8 business related flights per year (e.g. non-frequent flyers) represented by $6.5 \%$ of the sample. 
- Quintile 4: 8-18 business related flights per year (e.g. frequent flyers) represented by 22.3 $\%$ of the sample.

- Quintile 5: more than 18 business related flights per year (e.g. frequent flyers) represented by $69.5 \%$ of the sample.

Figure $\mathbf{2}$ - Kano's model of customer satisfaction

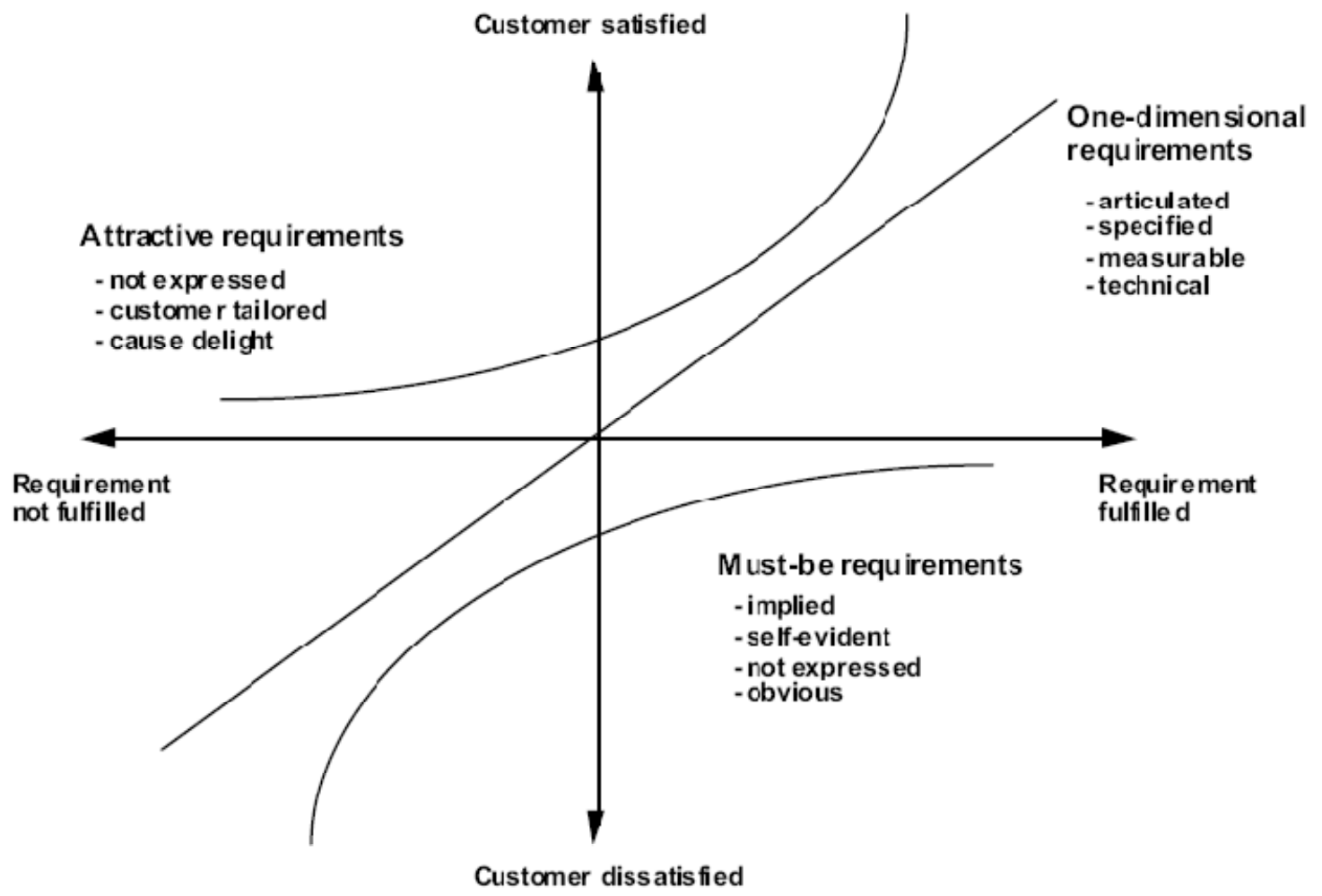

Source: Berger et al. 1993

Thus, the results are differentiated between the five quintiles of business air travels. The analyses are based on the fundamental hypothesis that the higher the punctuality, the higher is the probability that the punctuality becomes a basic factor. In other words with an increasing delay perspective punctuality becomes an enthusiastic factor with significant differences dependent on the number of business related flights. The rationale of the fundamental hypothesis lies in the fact that with an alternative perspective consisting of a 60 minute delay, a shorter or no delay evokes more enthusiasm then with a perspective of only a 15 minutes 
delay.

The data which are based on the Kano research method and thus split into basic, power and enthusiasm factors, were analysed to answer the fundamental hypothesis based on four hypothesis tests for each delay time perspective $(15,30,45$ and 60 minutes). For each a contingency analysis with chi-square independent test was conducted. The four hypothesis tests compare the punctuality and a 15,30, 45 or 60 minutes delay with the quintiles of the number of yearly business related flights.

\section{RESULTS AND DISCUSSION}

The results are based on the hypothesis tests for the four different levels of delays. First, a comparison between punctuality and a 15 minutes delay according to the quintiles of the number of yearly business related flight is analysed (Table 1 ).

The result with respect to an expected 15 minutes delay shows significantly that a reduction of the delay can create satisfaction linearly. The more frequent a person flies the more it becomes a power factor creating satisfaction. For a significant number of travellers a reduction of an expected 15 minutes delay does not create any satisfaction, but an increase of the delay creates dissatisfaction and thus for them it is a basic factor.

Second, a comparison between punctuality and a 30 minutes delay according to the quintiles of the number of yearly business related flights is analysed (Table 2).

The result with respect to an expected 30 minutes delay indicates that the more frequent a person flies for business purposes, the more a reduction of the delay is perceived as a linear gain of satisfaction. Still for a significant number of travellers a reduction of an expected 30 minutes delay does not create any satisfaction, but rather dissatisfaction if an increase of the delay happens and thus for them it is a basic factor. Up to 30 minutes expected delay creates linear satisfaction with a reduction of the delay and dissatisfaction if the delay is increased and longer than expected. 
Table 1 - Hypothesis test with regard to a 15 minutes delay

\begin{tabular}{l|l}
\hline HYPOTHESIS: & $\begin{array}{l}\text { The more often a person flies for business purposes per year, } \\
\text { the more critical respectively problematic are potential delays in } \\
\text { the flight offers. }\end{array}$ \\
\hline METHOD: & $\begin{array}{l}\text { Contingency analysis (cross tabulation) and Chi-Square } \\
\text { independent test for quintiles of the number of yearly business } \\
\text { related flights. Comparison of punctuality versus a delay of } 15 \\
\text { minutes. }\end{array}$ \\
\hline SAMPLING: & $\begin{array}{l}\text { All cases } \\
\text { RESULT: }\end{array}$ \\
$\begin{array}{l}\text { Quintile specific distribution of factor classification according to } \\
\text { the Kano approach. }\end{array}$
\end{tabular}

\section{Anova:}

$X^{2}=92.063 ;$ Sig. $=.000 ; C C=.211$

\begin{tabular}{|c|c|c|c|c|c|}
\hline $\begin{array}{l}\downarrow \text { Description } \\
\text { (flights) } \rightarrow\end{array}$ & $\begin{array}{l}1 . Q \\
(0.4)\end{array}$ & $\begin{array}{l}\text { 2. Q } \\
\text { (2) }\end{array}$ & $\begin{array}{l}\text { 3. Q } \\
(7.2)\end{array}$ & $\begin{array}{l}\text { 4. } Q \\
(18)\end{array}$ & $\begin{array}{l}\text { 5. Q } \\
(\infty)\end{array}$ \\
\hline Enthusiasm factor & $7.7 \%$ & $4.2 \%$ & $1.6 \%$ & $2.7 \%$ & $0.8 \%$ \\
\hline Power factor & $47.9 \%$ & $53.9 \%$ & $63.3 \%$ & $62.6 \%$ & $67.2 \%$ \\
\hline Basic factor & $24.7 \%$ & $27.5 \%$ & $25.3 \%$ & $21.0 \%$ & $24.9 \%$ \\
\hline $\begin{array}{l}\text { Indifferent, } \\
\text { questionable or contrary }\end{array}$ & $19.7 \%$ & $14.4 \%$ & $9.7 \%$ & $13.8 \%$ & $7.1 \%$ \\
\hline
\end{tabular}

INTERPRETATION: Hypothesis confirmed. 
Table 2 - Hypothesis test with regard to a 30 minutes delay

\begin{tabular}{l|l}
\hline HYPOTHESIS: & $\begin{array}{l}\text { The more often a person flies for business purposes per year, } \\
\text { the more critical respectively problematic are potential delays in } \\
\text { the flight offers. }\end{array}$ \\
\hline METHOD: & $\begin{array}{l}\text { Contingency analysis (cross tabulation) and Chi-Square } \\
\text { independent test for quintiles of the number of yearly business } \\
\text { related flights. Comparison of punctuality versus a delay of } 30 \\
\text { minutes. }\end{array}$ \\
\hline SAMPLING: & All cases \\
\hline RESULT: & $\begin{array}{l}\text { Quintile specific distribution of factor classification according to } \\
\text { the Kano approach. }\end{array}$
\end{tabular}

\section{Anova:}

$X^{2}=107.155 ;$ Sig.=.000; $C C=.227$

\begin{tabular}{|c|c|c|c|c|c|}
\hline $\begin{array}{l}\downarrow \text { Description } \\
\text { (flights) } \rightarrow\end{array}$ & $\begin{array}{l}1 . Q \\
(0.4)\end{array}$ & $\begin{array}{l}\text { 2. } Q \\
(2)\end{array}$ & $\begin{array}{l}\text { 3. Q } \\
(7.2)\end{array}$ & $\begin{array}{l}\text { 4. } Q \\
(18)\end{array}$ & $\begin{array}{l}\text { 5. Q } \\
(\infty)\end{array}$ \\
\hline Enthusiasm factor & $11.2 \%$ & $6.3 \%$ & $3.8 \%$ & $3.4 \%$ & $2.6 \%$ \\
\hline Power factor & $44.5 \%$ & $52.3 \%$ & $60.9 \%$ & $61.8 \%$ & $65.9 \%$ \\
\hline Basic factor & $23.4 \%$ & $26.3 \%$ & $23.9 \%$ & $20.5 \%$ & $24.9 \%$ \\
\hline $\begin{array}{l}\text { Indifferent, } \\
\text { questionable or contrary }\end{array}$ & $20.9 \%$ & $15.1 \%$ & $11.5 \%$ & $14.3 \%$ & $6.6 \%$ \\
\hline
\end{tabular}

INTERPRETATION: Hypothesis confirmed.

Source: Own research

Third, a comparison between punctuality and a 45 minutes delay according to the quintiles of the number of yearly business related flights is analysed (Table 3 ). 
Table 3 - Hypothesis test with regard to a 45 minutes delay

\begin{tabular}{l|l}
\hline HYPOTHESIS: & $\begin{array}{l}\text { The more often a person flies for business purposes per year, } \\
\text { the more critical respectively problematic are potential delays in } \\
\text { the flight offers. }\end{array}$ \\
\hline METHOD: & $\begin{array}{l}\text { Contingency analysis (cross tabulation) and Chi-Square } \\
\text { independent test for quintiles of the number of yearly business } \\
\text { related flights. Comparison of punctuality versus a delay of } 45 \\
\text { minutes. }\end{array}$ \\
\hline SAMPLING: & All cases \\
\hline RESULT: & $\begin{array}{l}\text { Quintile specific distribution of factor classification according to } \\
\text { the Kano approach. }\end{array}$
\end{tabular}

Anova:

$X^{2}=125.330 ;$ Sig.=.000; $C C=.244$

\begin{tabular}{|c|c|c|c|c|c|}
\hline $\begin{array}{l}\downarrow \text { Description } \\
\text { (flights) } \rightarrow\end{array}$ & $\begin{array}{l}1 . Q \\
(0.4)\end{array}$ & $\begin{array}{l}\text { 2. } Q \\
(2)\end{array}$ & $\begin{array}{l}\text { 3. Q } \\
(7.2)\end{array}$ & $\begin{array}{l}4 . Q \\
(18)\end{array}$ & $\begin{array}{l}\text { 5. Q } \\
(\infty)\end{array}$ \\
\hline Enthusiasm factor & $32.0 \%$ & $23.5 \%$ & $24.3 \%$ & $19.1 \%$ & $19.2 \%$ \\
\hline Power factor & $23.7 \%$ & $34.9 \%$ & $39.9 \%$ & $45.9 \%$ & $48.6 \%$ \\
\hline Basic factor & $12.8 \%$ & $16.9 \%$ & $13.7 \%$ & $14.0 \%$ & $19.7 \%$ \\
\hline $\begin{array}{l}\text { Indifferent, } \\
\text { questionable or contrary }\end{array}$ & $31.6 \%$ & $24.7 \%$ & $22.1 \%$ & $21.0 \%$ & $12.6 \%$ \\
\hline
\end{tabular}

INTERPRETATION: Hypothesis confirmed.

Source: Own research

The result with respect to an expected 45 minutes delay shows that it is still a power factor, meaning that there is a linear relation between a reduction of the delay and the satisfaction generated. For frequent business travellers it is rather a linear power factor, whereas for nonfrequent travellers an underbidding of an expected 45 minutes delay leads to a more then linear satisfaction gain being an enthusiasm factor for them. 
Fourth, a comparison between punctuality and a 60 minutes delay according to the quintiles of the number of yearly business related flights is analysed (Table 4). The result shows significantly that if a 60 minutes delay is expected, less delay creates more than average satisfaction whereas a higher than 60 minutes delay does not generate a lot more dissatisfaction. Thus, a reduction of delay, if a 60 minutes delay is expected creates an above average satisfaction.

Table 4 - Hypothesis test with regard to a 60 minutes delay

\begin{tabular}{l|l}
\hline HYPOTHESIS: & $\begin{array}{l}\text { The more often a person flies for business purposes per year, } \\
\text { the more critical respectively problematic are potential delays in } \\
\text { the flight offers. }\end{array}$ \\
\hline METHOD: & $\begin{array}{l}\text { Contingency analysis (cross tabulation) and Chi-Square } \\
\text { independent test for quintiles of the number of yearly business } \\
\text { related flights. Comparison of punctuality versus a delay of } 60 \\
\text { minutes. }\end{array}$ \\
\hline SAMPLING: & All cases \\
\hline RESULT: & $\begin{array}{l}\text { Quintile specific distribution of factor classification according to } \\
\text { the Kano approach. }\end{array}$
\end{tabular}

Anova:

$X^{2}=78.990 ;$ Sig.=.000; $C C=.196$

\begin{tabular}{|c|c|c|c|c|c|}
\hline $\begin{array}{l}\downarrow \text { Description } \\
\text { (flights) } \rightarrow\end{array}$ & $\begin{array}{l}1 . Q \\
(0.4)\end{array}$ & $\begin{array}{l}\text { 2. Q } \\
(2)\end{array}$ & $\begin{array}{l}3 . Q \\
(7.2)\end{array}$ & $\begin{array}{l}\text { 4. Q } \\
(18)\end{array}$ & $\begin{array}{l}\text { 5. Q } \\
(\infty)\end{array}$ \\
\hline Enthusiasm factor & $43.1 \%$ & $47.1 \%$ & $48.8 \%$ & $51.1 \%$ & $45.7 \%$ \\
\hline Power factor & $8.3 \%$ & $7.2 \%$ & $11.5 \%$ & $12.0 \%$ & $19.9 \%$ \\
\hline Basic factor & $2.2 \%$ & $6.5 \%$ & $4.3 \%$ & $4.3 \%$ & $6.0 \%$ \\
\hline $\begin{array}{l}\text { Indifferent, } \\
\text { questionable or contrary }\end{array}$ & $46.6 \%$ & $39.2 \%$ & $35.4 \%$ & $32.5 \%$ & $28.4 \%$ \\
\hline
\end{tabular}

INTERPRETATION: Hypothesis confirmed.

Source: Own research 
Practically this means that if expectations are set towards high delays, it is easier to create customer satisfaction by having less delay and there is no great impact on satisfaction by more delay. Thus, if airlines are known for their delay, they can create satisfaction more easily then if they are expected for being on time.

Overall the results of the four tests confirm that a perspective of a small systematic delay leads punctuality to be perceived as a basic factor, meaning that a reduction of delay can only prevent dissatisfaction. The perspective of a big delay leads punctuality to be perceived more and more as an enthusiasm factor, meaning that a decrease in the expected delay increases satisfaction more than linear.

In practice if airlines or airports announce a delay of an air connection especially a departure, it can influence the level of satisfaction of its passengers by the communication principle. If a delayed flight is expected to leave 45 minutes late, satisfaction can be created if passengers are told that the flight is expected to leave in 60 minutes at first and to a later stage in a further announcement passengers can be told, that the delay has been reduced by 15 minutes. Dissatisfaction is created, if passengers are told the plane is expected to leave in 30 minutes and in a second announcement a correction with an additional 15 minutes has to be communicated, as a further 15 minutes delay can in the best case only prevent dissatisfaction.

\section{SUMMARY AND CONCLUSIONS}

Travel time perception plays an important role in case of satisfaction or dissatisfaction in connection with delays. By specific communication strategies or attractions at the airports, delay can be perceived more or less negatively or even positively.

The research in this paper has identified different time perceptions of air travellers on business trips when it comes to delays related to the expected delay. Travel time is an important issue for frequent and non-frequent travellers and includes the whole trip from home to the end destination. Generally, a delay of 15 - 30 minutes is taken into account. Delays of more then thirty minutes are seen as bad and negatively influence the satisfaction level of business air travellers. Interestingly, the more frequent a passenger is travelling; a reduction of expected 
delays up to thirty minutes creates satisfaction. It cannot be generalised though, that delays up to thirty minutes create satisfaction. For a significant number of respondents a reduction of the expected delay just prevents from dissatisfaction. If delays of more than thirty minutes up to sixty minutes are expected, a reduction of the delay results in a linear and sometimes even more than average increase of satisfaction compared to the amount of time of reduction.

For airlines and airports it can be concluded that time delays should rather be announced as longer time delays than expected and then if the plane is earlier reduced the exact delay. By this, less dissatisfaction arises; even a chance of creating satisfaction is given. By announcing a delay and later on postpone a departure again by another delay creates dissatisfaction. Hence, by introducing an ingenious delay communication procedure, passengers might become more satisfied with their air travel.

\section{REFERENCES}

- Bamberg, S., Rolle, D., Weber, Ch., (2003), Does Habitual Mode Use Not Lead to More Resistance to Change of Travel Mode? Transportation. 30 (1), 97-108.

- Berger, Ch., Blauth, R., Boger, D., Bolster, Ch., Burchill, G., DuMouchel, W., Pouliot, F., Richter, R., Rubinoff, A., Shen, D., Timko, M., Walden, D., (1993), Kano's methods for understanding customer-defined quality, Center for Quality Management Journal, Vol. 4, pp. 3-36.

- Ben-Akiva, M., Morikawa, T., (2002), Comparing ridership attraction of rail \& bus. Transport Policy. 9 (2), 107-117.

- Einstein, A. (1916), Die Grundlage der allgemeinen Relativitätstheorie. In: Annalen der Physik. 49, 1916, S. 769-822

- Fishbein, M., Ajzen, I., (1975), Belief, Attitude, Intention and Behaviour: An Introduction to Theory and Research. Addison-Wesley Publishing Company, Inc.

- Heggie, I.G. (1977), Putting behaviour into behavioural models of travel choice. Transport Studies Unit Working Paper \#22, Oxford: School of Geography.

- Hensher, D.A. (1997), The value of business travel time. Oxford: Pergamon Press. 
- Werthner, H.; Klein, S. (2006), Tourism innovations enabled by information and communication technologies. In: Walder, B.; Weiermair, K.; Sancho Pérez, A. (Hrsg.) Innovation and Product Development in Tourism. Berlin, Erich Schmidt: 71-84.

- Laesser, Ch. (2006), Rolle und Bedeutung von Zeit im Verkehr: Eine Einführung, Schweizerische Verkehrswissenschaftliche Gesellschaft, Presentation, SVWG Conference 2006, Bern.

- Laesser, C., Wittmer, A. (2006), Die Bedeutung des Flughafens Zürich und dessen Flugangebot für die Standortattraktivität. St. Gallen: CFAC-HSG, IDT-HSG.

- Last, J., Manz, W. (2003), Unselected mode alternatives: What drives modal choice in long-distance passenger transport? Paper presented at the 10th International Conference on Travel Behaviour Research, Lucerne, August 2003.

- Mackie, P. J., Fowkes, A. S., Wardman, M., Whelan, G., Nellthorp, J., (2003), Value of time savings in the UK - Summary report. UK Department of Transport Research Report.

- Mandel, B., Gaudry, M., Rothengatter, W. (1997), A disaggregate Box-Cox logit mode choice model of intercity passenger travel in Germany $\&$ its implications for high-speed rail dem\& forecasts. The Annals of Regional Science 31 (2) 99-120.

- Sauerwein, E., Bailom, F., Matzler, K., Hinterhuber, H.H., (1996), The Kano Model: How to delight your customers. In: Preprints Volume I of the IX. International Working Seminar on Production Economics Vol. 1. Innsbruck. 